"you don't remember me," she says,

"but ten years ago i saw you drinking beer

with allen ginsberg in the $49 \mathrm{er}$ tavern."

i say, "i've never met ginsberg.

are you sure it wasn't bukowski?

maybe ferlinghetti, everson, or edward field?"

"oh no," she says, "it was ginsberg all right."

"maybe it wasn't me. maybe it was chuck stetler

or elliot fried or leo mailman or david barker

or ray zepeda or hubert 11oyd."

"oh no," she says, "it was you all right, and it was ginsberg you were drinking with."

i feel her ample tit against my elbow.

you know it's amazing how you can even forget something memorable

like drinking beer with allen ginsberg.

\title{
REVISED STANDARD VERSION
}

He was looking up the correct pronunciation of "maleficent" in the dictionary his wife had bought him for Father's Day when he noticed that the word "male"

was no longer included.

He paged rapidly in search of "virility"

and, in growing panic, he scanned for "manly."

But he couldn't even come up with "man,"

let alone "testes," "testosterone," or "penis."

"Macho" was in there though,

defined as "an archaism for an obsolete obscenity."

When he came upon "boy" defined as

"archaic diminutive for an obsolete 'type'

of young woman,"

he knew the war was over.

He thought of running a white flag

up his now un-named member,

but of course it wouldn't stand for it. 